www.jmscr.igmpublication.org

Impact Factor 3.79

Index Copernicus Value: 5.88

ISSN (e)-2347-176x ISSN (p) 2455-0450

crossref DOI: _http://dx.doi.org/10.18535/jmscr/v4i02.61

Journal Of Medical Science And Clinical Research

\title{
Impacted Foreign Body in Frontal Sinus- A Rare Case Report
}

\section{Authors \\ Dr Gourav Popli ${ }^{1}$, Dr Prajesh Dubey ${ }^{2}$, Dr Vishal Bansal ${ }^{3}$, Dr Avi Bansal ${ }^{4}$, Dr Tarun Gupta ${ }^{5}$, Dr Sahil Kapoor ${ }^{6}$}

${ }^{1}$ Senior Lecturer, Department of Oral and Maxillofacial Surgery, Subharti Dental College, Meerut

${ }^{2}$ Reader, Department of Oral and Maxillofacial Surgery, Subharti Dental College, Meerut

${ }^{3}$ Professor and Head, Department of Oral and Maxillofacial Surgery, Subharti Dental College, Meerut

${ }^{4}$ Senior Lecturer, Department of Oral and Maxillofacial Surgery, Subharti Dental College, Meerut

${ }^{5}$ Senior Lecturer, Department of Public Health and Community Dentistry, M.M College of Dental Sciences and Research, Ambala

${ }^{6}$ Postgraduate Student, Department of Oral and Maxillofacial Surgery, Subharti Dental College, Meerut Corresponding Author and Reprints

Dr Gourav Popli (Senior Lecturer)

Department of Oral and Maxillofacial Surgery

Subharti Dental College, Swami Vivekanand Subharti University, Meerut India

Email-drgp0250@gmail.com Phone No:- +918475991147

\begin{abstract}
Foreign bodies embedded in the paranasal sinuses, especially in the frontal sinus are uncommon. We report a case of windshield glass embedded in the frontal sinus but was not involving the posterior wall of sinus or frontal lobe, as observed in the CT scans. Due consideration was given to remove the entire glass as one piece. However, small fragments broke off, which were removed with repeated and thorough examination of the sinus. We emphasize the importance of thorough clinical examination, appropriate radiographic techniques and an endeavour to remove the foreign body In Toto.

Keywords- Foreign body, Frontal sinus, Glass.
\end{abstract}

\section{Introduction}

Frontal sinus is frequently involved in facial trauma due to its prominent position on face. ${ }^{1}$ Foreign body penetrations in head and neck region may include oral aperture, ear, nose, eyes and paranasal sinuses. However, involvement of paranasal sinuses is rare with maxillary sinus being most commonly involved amongst the other ones. $^{2}$ Approximately $50 \%$ of these foreign bodies involve maxillary sinus, however frontal, ethmoid, sphenoid sinus involvement is rare and account for nearly equal reported cases. ${ }^{3}$ Foreign body in maxillofacial region mostly results from penetrating/ high velocity injuries. ${ }^{4}$ Maxillofacial trauma accounts for $70 \%$ of the foreign bodies and remaining $30 \%$ have been due to dental 'procedures of maxilla. ${ }^{2}$ Foreign body including glass particles, gunshot pellet, stones etc involving 
frontal sinus have been reported in English Literature. ${ }^{3,5,6}$ We report a case of wind shield glass lodgement and its removal from the frontal sinus immediately post trauma and intend to discuss the anticipated complications related to foreign body in frontal sinus.

\section{Case Report}

A patient reported to Emergency with an alleged history of car accident. Patient was under the influence of alcohol at the time of presentation but was oriented to time, place and person. There was no history of loss of consciousness, vomiting or seizures. There was a laceration of approximately $7 \mathrm{~cm}$ below both the eyebrows and crossing the glabella. Patient also complained of extreme pain on moving his left leg which was later diagnosed as hip joint dislocation by the orthopaedic surgeon. Thorough examination of the facial laceration revealed a glass piece embedded axially deep into the frontal bone. CT face with 3-D reconstruction revealed a hyper dense object approximately $3.5 \mathrm{~cm}$ of length involving the frontal sinus and fortunately not crossing the posterior wall of frontal sinus. CT scan head presented no sign of any head injury. Patient was shifted to emergency operation theatre without much delay, wound was irrigated thoroughly with hydrogen peroxide, normal saline, betadine solution. In an attempt to remove the object In Toto, few fragile glass particles broke off and a large piece was retrieved. Remaining glass pieces (seven) were removed carefully after repeated examination and irrigation. Sinus lining was curetted out and frontal sinus was packed with gelatin foam. Closure was done with 5-0 prolene suture to avoid any scar in aesthetic zone. Followup one month revealed uneventful recovery. Due to non compliance of patient, further follow up was not feasible.

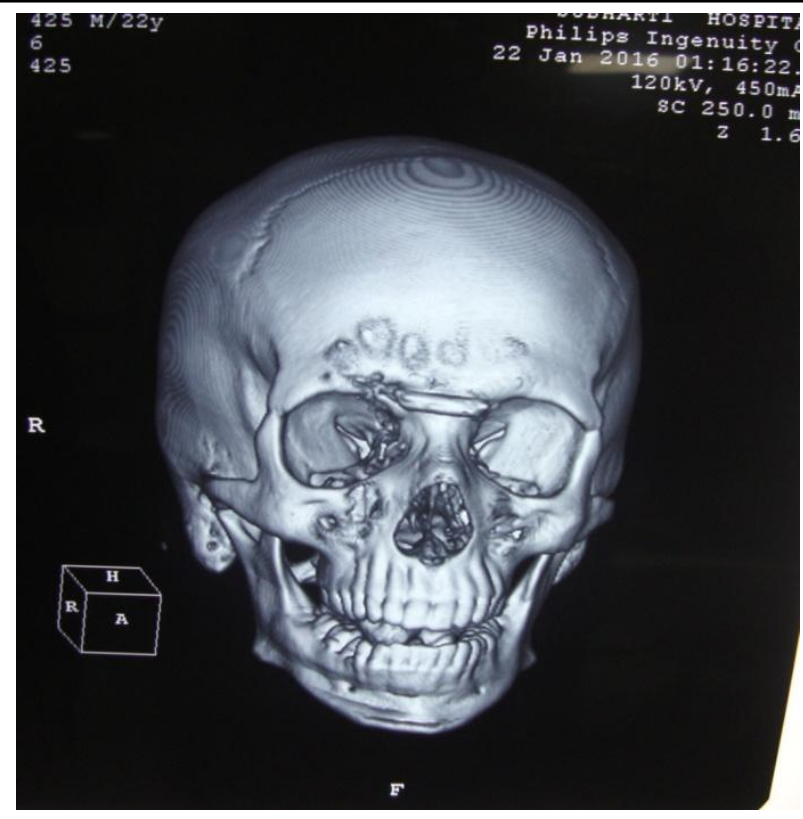

Figure 1- CT Face with 3-D reconstruction showing an impacted foreign body embedded axially in the frontal bone.

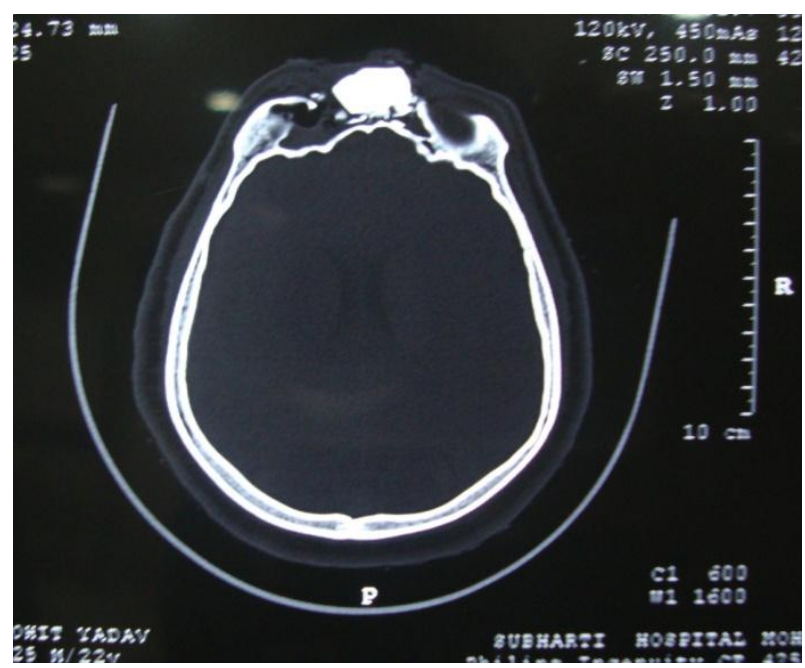

Figure 2- Axial view of CT Scan Head showing a hyper dense foreign body in frontal sinuses but not involving the posterior wall or anterior cranial fossa. 


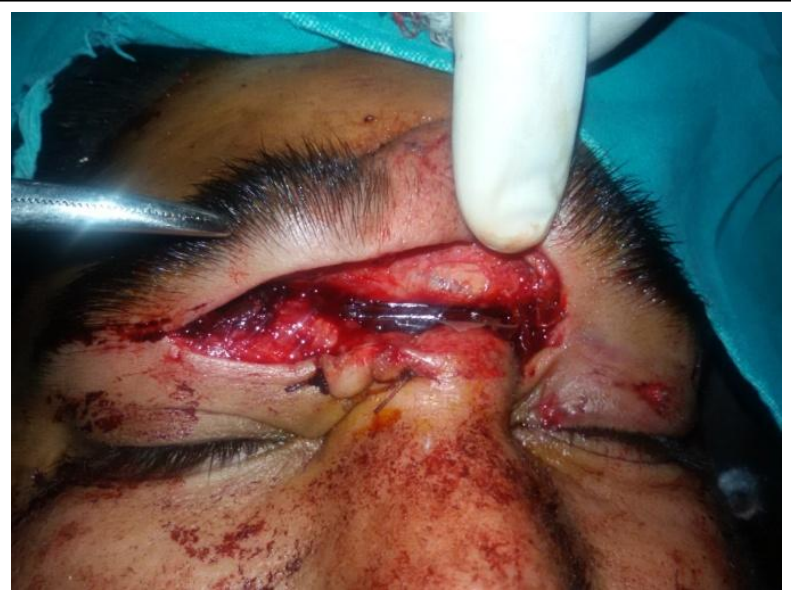

Figure 3- Clinical image representing the Impacted glass piece

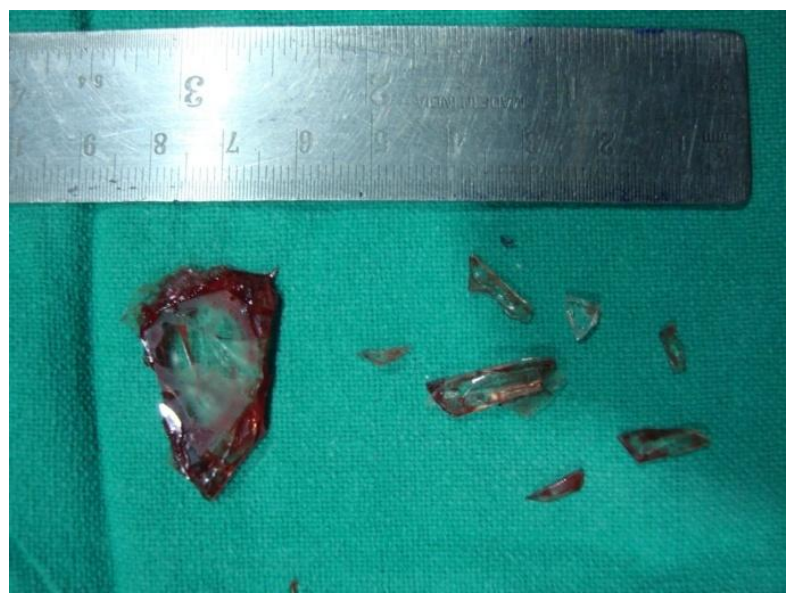

Figure 4- A major glass piece and seven small pieces which broke off during retrieval

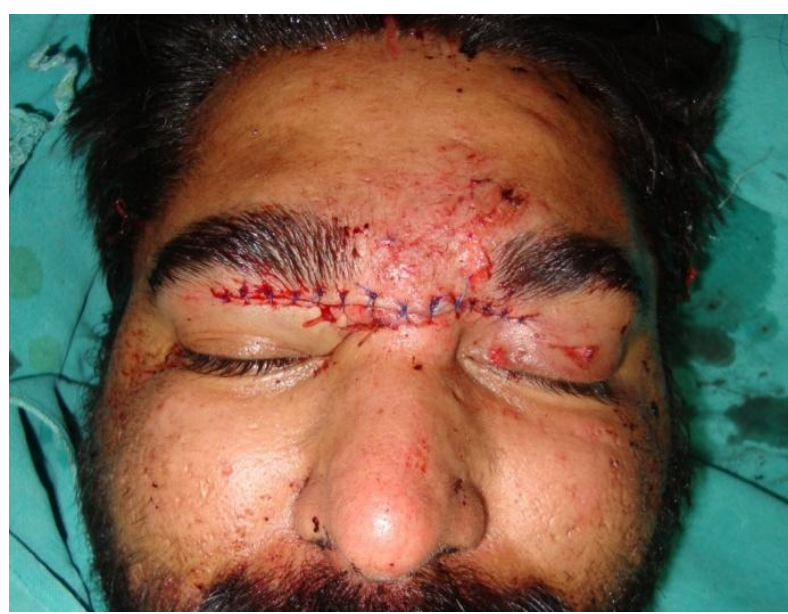

Figure 5 Post-operative image after closure of the wound with 5-0 Prolene suture

\section{Discussion}

Head injuries are commonly associated with other facial fractures. ${ }^{7}$ It has been observed that frontal sinus is traumatized in $12-15 \%$ of significant head injuries. ${ }^{8}$ Foreign bodies in frontal sinus are rare but with increasing number of road traffic accidents, they may become more common. ${ }^{3}$ Graces et al recommended that foreign bodies should be suspected in even seemingly trivial lacerations in cases of maxillofacial trauma. ${ }^{2}$ Injuries or foreign body penetrations of frontal sinus is of particular concern because of close proximity of anterior cranial fossa duramater and frontal lobe to the posterior sinus wall. So, it becomes essential to properly diagnose and manage the frontal sinus injury to avoid serious immediate or delayed complications. ${ }^{1}$ Hidden, unrecognized foreign bodies, if not properly diagnosed at the time of trauma can lead to various delayed complications like front nasal duct obstruction, Osteomyelitis, thrombophlebitis of frontal lobe, meningitis, extradural, subdural and frontal lobe abscess. ${ }^{3,9}$ Thus, a high index of suspicion is necessary for maxillofacial surgeons to correctly diagnose foreign bodies embedded in the frontal sinus. ${ }^{10}$

The importance of complete wound exploration with frontal sinus trauma should not be overlooked. Digital palpation through the wound, assisted with direct visualization of underlying bone should be performed whenever there is suspected penetrating trauma to frontal sinus. As well as, suitable diagnostic radiographs should also be performed in such injuries. ${ }^{10}$ Computed tomography head is indicated as it not only defines bony deformities, but also provides useful information regarding size of foreign body, its intracranial extent and helps to assess the integrity of anterior and posterior wall of sinus. ${ }^{3,11}$

It is suggested that entire foreign body should be removed In Toto as any small hidden particle may lead to delayed complications. As delayed cases of fistula or infection secondary to a foreign body in frontal sinus have been reported even after 50 years of lodgement in English literature. ${ }^{12}$ Thus, 
we paid a generous attention to removal of windshield glass in its intact form as it was lodged in the sinus. However, some small particles (seven) broke off during retrieval, as the glass was strongly impacted in the sinus, which were removed vigilantly with repeated examination and irrigation.

\section{Conclusion}

Penetrating trauma to the frontal sinus may result in injury to the underlying duramater and brain. Moreover, any remaining hidden foreign body has also been implicated for various delayed complications. Radiographic evaluation, in combination with a thorough wound exploration should be carried out when the potential for a penetrating injury to frontal sinus exists. We recommend that for all maxillofacial trauma patients with skin lacerations over the paranasal sinuses, suspicion of foreign bodies and their removal In Toto is critical to prevent intrasinus and intracranial complications. Authors believe that, present case report will add on to the existing literature and will help both the academicians and clinicians in the management of impacted foreign bodies in the frontal sinus.

\section{Source(s) of support or funding: None \\ Conflicting Interest: Nil \\ Acknowledgement: None}

\section{References}

1. Alan S Kaplan, J Douglas Green, Thomas V McCaffrey. Unsuspected foreign body in the frontal sinus and anterior cranial fossa. Annals of Emergency Medicine 1989; 18: 9: 988-990.

2. Graces SM, Norris CW. Unusual frontal sinus foreign body. J Laryngol Otol 1972; 86(12): 1265-1268.

3. Onerci M, Ogretomenoglu O, Yilamaz T. Glass in the frontal sinus: report of three cases. Laryngol Otol 1997; 111(2): 156158.
4. Agarwal AK, Passey JC, Sethi A. CSF leak following extraction of a longstanding fronto-orbital bullet: A case report. The Internet Journal of Otorhinolaryngology 2006; 4(2).

5. Gadre KCL, Odaya JD, Deshpande CK. Foreign body (stone) in the frontal sinus. J Laryngol Otol 1963; 77: 146.

6. Gonul, et al. Tension pneumocephalus after frontal sinus gunshot wound. Otolaryngol Head Neck Surg 1998; 118(4): 559-561.

7. Peri G, Chabannes J, Menes R. Fractures of the frontal sinus. J Maxillofac Surg 1981; 9: 73-80.

8. May M, Ogura JH, Schramm V. Nasofrontal duct in frontal sinus fracture. Arch Oto-laryngol 1970; 92: 534-538.

9. Lancer JM. Glass in the foreign body in the frontal sinus. J Laryngol Otol 1982; 96: 357-360.

10. Adkins WY, Cassone RD, Putney FJ. Solitary frontal sinus fractures. Laryngoscope 1979; 89: 1099-1104.

11. Rowe LD, Miller E, Brandt-Zawadski M. Computed tomography in maxillofacial trauma. Laryngoscope 1981; 91: 745-757.

12. Issac J Rudloe, Richard J Hesse, Jefferson Kaye. Frontal sinus fistula secondary to a cranial foreign body. The Ochsner Journal 2007; 7(1): 33-34. 